
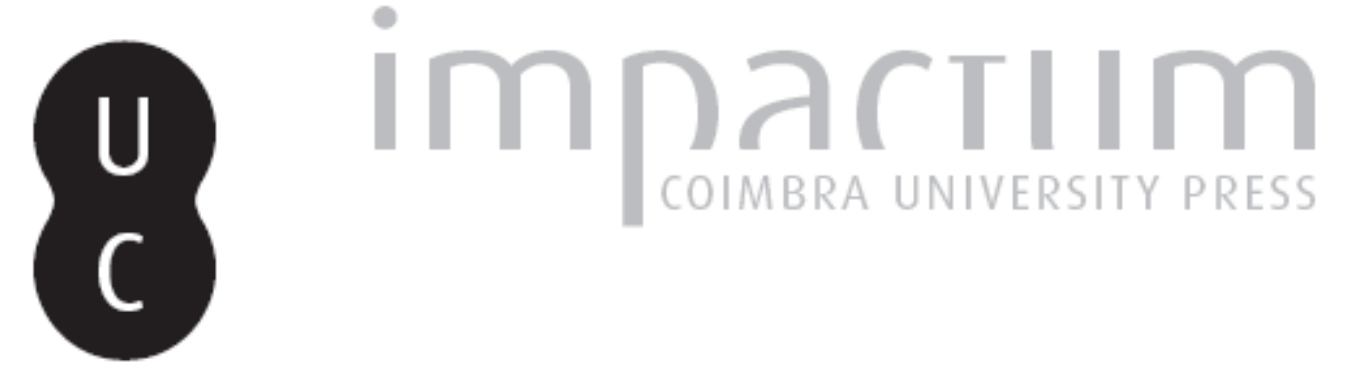

\title{
Cerâmicas ditas campanienses e de imitação conservadas no Museu Regional de \\ Sintra
}

Autor(es): $\quad$ Sousa, Élvio Melim de

Publicado por: Imprensa da Universidade de Coimbra

URL persistente:

URI:http://hdl.handle.net/10316.2/45441

DOI:

DOI:https://dx.doi.org/10.14195/1647-8657_35_2

Accessed : $\quad$ 26-Apr-2023 13:29:33

A navegação consulta e descarregamento dos títulos inseridos nas Bibliotecas Digitais UC Digitalis, UC Pombalina e UC Impactum, pressupõem a aceitação plena e sem reservas dos Termos e Condições de Uso destas Bibliotecas Digitais, disponíveis em https://digitalis.uc.pt/pt-pt/termos.

Conforme exposto nos referidos Termos e Condições de Uso, o descarregamento de títulos de acesso restrito requer uma licença válida de autorização devendo o utilizador aceder ao(s) documento(s) a partir de um endereço de IP da instituição detentora da supramencionada licença.

Ao utilizador é apenas permitido o descarregamento para uso pessoal, pelo que o emprego do(s) título(s) descarregado(s) para outro fim, designadamente comercial, carece de autorização do respetivo autor ou editor da obra.

Na medida em que todas as obras da UC Digitalis se encontram protegidas pelo Código do Direito de Autor e Direitos Conexos e demais legislação aplicável, toda a cópia, parcial ou total, deste documento, nos casos em que é legalmente admitida, deverá conter ou fazer-se acompanhar por este aviso.

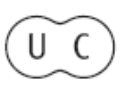


UNIVERSIDADE DE COIMBRA

FACULDADE DE LETRAS

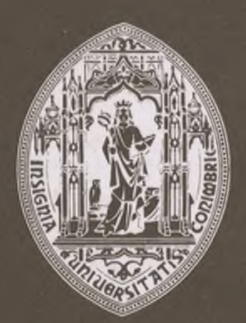

\section{CONIMBRIGA}

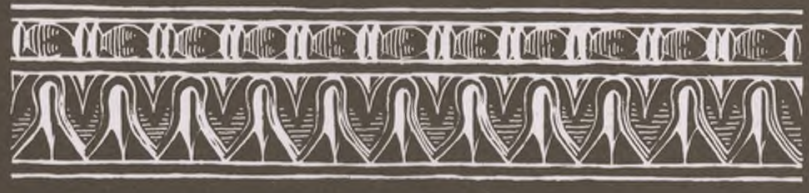

VOLUME XXXV - 1996 
Élvio Melim De SousA

Conservador dos Museus da Câmara Municipal de Sintra

CERÂMICAS DITAS CAMPANIENSES E DE IMITAÇÃO CONSERVADAS

NO MUSEU REGIONAL DE SINTRA

"Conimbriga" XXXV (1996) p. 37-58

RESUMO: Estudam-se, neste artigo, 23 peças de cerâmica campaniense e de imitação campaniense conservadas no Museu Regional de Sintra. A partir da análise destas cerâmicas, revê-se a cronologia atribuída à romanização da zona $\mathrm{W}$ do municipium Olisiponense recuando-a até níveis plenos do século III a. C. Elabora-se ainda, com base na bibliografia disponível e em algumas informações, uma carta de dispersão geográfica das cerâmicas campanienses e de imitação detectadas em Portugal.

RESUMÉ: On étudie, dans cet article, 23 tessons de céramique campanienne et d'imitation campanienne qui appartienent au Museu Regional de Sintra.

Avec l'analyse de ces céramiques on fait la révision de la chronologie de la romanisation de la région ouest du Municipium Olisiponense en l'abaissant jusqu'à des niveaux pleins du III siècle avant a. C.

On elabore, aussi, avec des données bibliographiques et autres, une carte de dispersion géographique de la céramique campanienne et d'imitation trouvée au Portugal.

Conimbriga, 35 (1996) 37-58 
(Página deixada propositadamente em branco) 


\section{CERÂMICAS DITAS CAMPANIENSES E DE IMITAÇÃO CONSERVADAS NO MUSEU REGIONAL DE SINTRA}

\section{ORIGEM E TIPOS DE FABRICOS}

As cerâmicas ditas campanienses surgem durante o século IV a. C., seguindo as tradições e o reportório formal das cerâmicas áticas de verniz negro, geralmente muito elegantes e de boa qualidade.

Tradicionalmente dividida em três classes distintas ('), as cerâmicas campanienses cobrem um período mediado entre o século IV a. C. e os finais do século I a. C.(cerca de 30 a. C.), altura em que se dá o "aparecimento" da sigillata aretina:

Campaniense A - de origem napolitana e executada com barro vermelho-acastanhado proveniente da Ilha de Ischia, apresenta verniz negro de óptima qualidade com reflexos observáveis. Fabricada entre o século IV a. C. e 40 a. C., esta classe foi bastante difundida pelo Mediterrâneo;

Campaniense B - suspeita-se, neste caso, de uma produção etrusca muito homogénea nas suas características ceramológicas, apresentando pasta acastanhada clara e verniz negro azulado. Produzida, talvez, a partir de inícios/meados do século II a. C., perdura até 50/30 a. C. Foi largamente difundida e imitada;

Campaniense $\mathbf{C}$ - originária da região de Siracusa, tem o seu fabrico situado durante os séculos II e I a. C. Possui pasta acinzentada

(') N. LAMbogLIA, em 1950, publica a primeira tipologia válida para estas cerâmicas (= "Classificazione Preliminare"), dividindo-as em três categorias - A, B e $\mathrm{C}$-, a qual ainda hoje é usada comummente. 
clara e verniz muito negro. Aceita-se, hipoteticamente, o facto de ter perdurado por estratos cronológicos superiores ao século I a. C.

Conhecem-se, todavia, inúmeros outros fabricos de "verniz negro", subsidiários e/ou aparentados com as cerâmicas campanienses - mais de 50 - , os quais aparecem descritos por Jean-Paul MOREL $\left({ }^{2}\right)$, se bem que não se aplique a estas produções a "divisória" de Nino LAmBoglia $\left({ }^{3}\right)$ para as cerâmicas campanienses.

\section{DISPERSÃO GEOGRÁFICA NO TERRITÓRIO PORTUGUÊS}

As estações portuguesas onde foram já exumadas cerâmicas campanienses não são numerosas, mas obedecem, ao que se sabe, a uma dispersão sul/norte, e aparecem em tipos diversos de estações que se estendem por todo o território hoje português.

Devem-se a M. DELGADO $\left({ }^{4}\right)$, e a O. da VEIGA FERREIRA $\left({ }^{5}\right)$, de certo modo, os primeiros inventários, em 1971, de estações portuguesas que forneceram cerâmicas ditas campanienses ou de imitação. Surgem, então, referências a vários locais essencialmente situados a Sul do Tejo, correspondendo, por sua vez, a maior parte dos fragmentos detectados, a peças insertas em colecções conservadas em museus.

Todavia, é M. MAIA $\left({ }^{6}\right)$, na sua tese de doutoramento, em 1987, quem fornece a mais completa carta de distribuição das cerâmicas campanienses e de imitação detectadas entre nós. Este autor, embora se reporte essencialmente à área a Sul do Tejo, congrega a maior parte dos locais, já conhecidos anteriormente, com outros onde o próprio teria efectuado ou tido conhecimento de recolhas.

Não sendo nossa intenção fazer aqui uma carta de dispersão geográfica exaustiva destes fabricos, conseguimos, ainda assim, apurar a detecção de cerâmicas campanienses e/ou de imitação de campaniense, em 69 locais, com base na bibliografia consultada e em algumas informações que nos foram amavelmente cedidas (cfr. mapa de distribuição):

(2) J. P. MOREL, 1981, pp. 47-51.

(3) N. LAMBOGLIA, 1952.

(4) M. DELGado, 1971, pp. 403-420.

$\left(^{5}\right)$ O. da Veiga Ferreira, 1971, pp. 313-332.

(') M. MAIA, 1987, voi. 2, pp. 52-83. 
1 - Alcácer do Sal; M. DELGADO, 1971, pp. 403-420.

2 - Almaraz (Almada); informação cedida pelo nosso colega Luís Barros, a quem agradecemos.

3 - Almodovar; M. Delgado, 1971, pp. 403-420.

4 - Antanhol (Coimbra); M. B. LloRIs, 1990, p. 47, mapa 2.

5 - Armés (Sintra); M. MAIA, 1978, vol. II, pp. 52-83.

6 - Baesuris; A. ARRUDA, 1986, pp. 401-406.

7 - Balsa; M. MAIA, 1987, vol. II, pp. 52-83.

8 - Beja a Pequena (São Salvador, Beja); $i d$., $i b$.

9 - Cabeça de Vaiamonte (Monforte); M. DELGADO, 1971, pp. 403-420.

10 - Cacilhas (Fábrica de Salga de Peixe) [Almada]; informação cedida pelo nosso colega Luís Barros, a quem agradecemos.

11 - Casal de Pianos - Pombal (Sintra).

12 - Casal do Silvério (Sintra); O. da Veiga Ferreira, 1971, pp. 315, 319 e 320; M. MAIA, 1987, vol. II, pp. 52-83; J. CARDIM RIBEIRO, 1982-83, p. 425, nota 3. Este local de recolha de cerâmica campaniense foi identificado primeiramente como "Pedra Furada" por O. da VEIGA FERREIRA (1971), distando cerca de $1,5 \mathrm{~km}$ do Casal do Silvério (cfr. J. CARDIM RIBEIRO, 1982-83, p. 425, nota 3).

13 - Castelinho dos Mouros (Castro Verde); M. MAIA, 1987, vol. II, pp. 52-83.

14 - Castelo da Lousa (Mourão); M. DELGADO, 1971, pp. 403-420.

15 - Castelo das Juntas (Castro Verde); M. MAIA, 1987, vol. II, pp. 52-83.

16 - Castelo de Arruda dos Vinhos (Arruda dos Vinhos); informação cedida pelo Dr. João Ludgero Marques Gonçalves, a quem agradecemos. Referente a recolhas efectuadas durante as escavações que decorreram em 1979.

17 - Castelo do Manuel Galo (Mértola); M. MAIA, 1987, voi. II, pp. 52-83.

18 - Castelo Velho de Safara (Moura); $i d$., $i b$.

19 - Castelo Velho do Cobres (Castro Verde); $i d$., ib.

20 - Castelo Velho do Roxo (Aljustrel); $i b$.

21 - Castro da Azougada (Moura); O. da Veiga Ferreira, 1971, pp. 313-332.

22 - Castro da Mangancha (Aljustrel); $i b$. 
23 - Castro da Mesa dos Castelinhos (Ourique); $i b$.

24 - Castro da Rotura (Palmeia); $i b$.

25 - Castro de Chibanes (Palmeia), $i b$.

26 - Castro de Romariz (Santa Maria da Feira); A. C. FERREIRA DE ALMEIDA, 1986, pp. 134-136.

27 - Castro de Segóvia (Caia e São Pedro, Eivas); M. MAIA, 1987, vol. II, pp. 52-83.

28 - Castro do Salvador (Cadaval); informação cedida pelo Dr. João Ludgero Marques Gonçalves, a quem agradecemos. Referente a recolhas efectuadas durante os trabalhos de escavação arqueológica de 1980.

29 - Castro dos Ratinhos (Moura); O. da VEIGA FERREIRA, 1971, pp. 313-332.

30 - Cerro da Vila (Quarteira, Loulé); informação cedida pelo Dr. A. M. Dias Diogo, a quem agradecemos.

31 - Cerro do Cavaco (Tavira); M. MAIA, 1987, vol. IL, pp. 52-83.

32 - Chões de Alpompé (Santarém); O. da VEIGA FERREIRA, 1971, pp.313-332.

33 - Cidade Velha de Santa Luzia (Viana do Castelo); A. C. FERREIRA DE ALMEIDA, 1986, pp. 134-136.

34 - Cividade de Lanheses (Viana do Castelo); C. A. BROCHADO DE ALMEIDA, 1990, pp. 198, 199, 275 e 276.

35 - Cola (Ourique); M. MAIA, 1987, vol. II, pp. 52-83.

36 - Conimbrigcr, M. DELGADO, 1971, pp. 403-420.

37 - Coto da Pena (Caminha); C. A. Ferreira DE Almeida, 1986, pp.134-136.

38 - D. Pedro (Beja); M. MAIA, 1987, vol. II, pp. 52-83.

39 - Ermidas (Sintra); $i d ., i b$.

40 - Foz do Arade (Portimão); A. M. Dias DlOGO e J. P. CARDOSO, 1992, pp. 9-11.

41 - Freiría (Cascais); informação cedida pelo nosso colega Guilherme Cardoso, a quem agradecemos.

42 - Granja dos Serrões (Sintra).

43 - Funchal (Sintra).

44 - Ilhéu do Rosário (Silves); M. MAIA, 1978, vol II, pp. 52-83.

45 - Lomba do Canho (Arganil); M. Delgado, 1971, pp. 403-420. Não é feita qualquer referência exacta à Lomba do Canho, mas sim a um "acampamento romano perto de Arganil", tendo-se deduzido, aqui, tratar-se daquela estação arqueológica. 


\section{6 - Lugar do Marcador (Sintra).}

47 - Mir obriga, id., ib. M. B. LlORIS (1990) refere no seu mapa de distribuição Santiago do Cacém, local que se deduz significar Mirobriga naquela carta. Por esta razão não o inserimos isoladamente nesta listagem.

48 - Miroiços (Cascais); informação cedida pelo nosso colega Guilherme Cardoso, a quem agradecemos.

49 - Monte Molião (Lagos); M. MAIA, 1987, voi. II, pp. 52-83.

50 - Myrtilis; id., ib.

51 - Olisipo', id., ib. Não sabemos a que local ou locais precisos dentro da urbs se refere M. MAIA (1987) quando enumera Olisipo. Pelo nosso lado, conseguimos apurar a detecção de cerâmicas campanienses nas termas dos Cássios, no teatro romano, nas Portas do Sol, na Rua dos Fanqueiros (informações cedidas pelo Dr. Dias Diogo, a quem agradecemos) e no Núcleo Arqueológico da Rua dos Correeiros/BCP (informação cedida pelo Dr. dementino Amaro, a quem se agradece).

52 - Outeiro de Polima (Cascais); informação cedida pelo nosso colega Guilherme Cardoso, a quem agradecemos.

53 - Pax Iulia, M. MAIA, 1987, vol. II, pp. 52-83.

54 - Pedra da Atalaia (Santiago do Cacém); C. TAvares DA SILVA, 1978, pp. 117-132.

55 - Pedrão (Setúbal); M. DELGADO, 1971, pp. 403-420. Esta autora, no artigo atrás indicado, refere apenas Setúbal. Todavia, em 1975, no Cap. VII do "A Propos des Céramiques de Conimbriga", J. SOARES (p. 92), na sua intervenção, fala de achados campanienses no Pedrão, os quais correspondem, certamente, aos enumerados por M. DELGADO como provenientes de Setúbal.

56 - Pisões (Beja); M. MAIA, 1987, vol. II, pp. 52-83.

57 - Porto do Sabugueiro (Muge); id., ib.

58 - Represas (Beja); $i d$., $i b$.

59 - Rocha Branca (Portimão); $i d$., ib.

60 - São Marcos (Sintra); id., ib.

61 - São Miguel de Odrinhas (Sintra); $i d$., $i b$.

62 - São Paulo (Gruta artificial) [Almada]; informação cedida pelo nosso colega Luís Barros, a quem agradecemos.

63 - São Pedro de Caldeias (Tomar); S. da PONTE, 1988, pp. 81 e 82.

64 - Scallabis', A. M. DÍAS DIOGO, 1984, pp. 111-143.

65 - Sines; C. Tavares da Silva e J. Soares, 1993, pp. 178 e 187 , nota 106. 
66 - Sirpens; M. MAIA, 1987, vol. II, pp. 52-83.

67 - Tróia de Setúbal (Grândola); informação cedida pelo Dr. Eurico Sepulveda, a quem se agradece.

68 - Veiros (Estremoz); id., ib.

69 - Villa Romana das Neves (Castro Verde); id., ib.

Denota-se uma predominância esmagadora de locais situados a Sul do Tejo - 64\% do total (= 44 estações) -, contra apenas 25 locais situados a Norte daquele rio - $=36 \%$ do total - , o que, em nosso entender, é aceitável, dada a sua difusão ser essencialmente marítima e mediterrânica.

Ainda assim, achamos provável que se venham a descobrir novos fragmentos de cerâmicas campanienses e/ou de imitação em estações localizadas sobretudo a Norte do Tejo, dada a grande produtividade e difusão que as mesmas conheceram.

É bem visível, de igual modo, a concentração de estações nas áreas geográficas localizadas no litoral do nosso território ou relativamente perto deste - panorama observável de Norte a Sul -, à excepção do Baixo Alentejo, sobretudo na região entre o Guadiana e o Sado, correspondendo esta convergência, talvez, não só à grande densidade de prospecção arqueológica, como também à sua manifesta riqueza mineral e relativa proximidade ao Mediterrâneo, bem como à consequente facilidade de penetração para o interior.

Outro aspecto digno de realce é a individualização da região do municipium Olisiponense, onde se concentra um número significativo de estações fornecedoras de cerâmicas campanienses ou de imitação, e ligadas, obviamente, a Olisipo e ao Tejo.

De salientar ainda o papel fundamental dos rios Guadiana, Sado, Tejo e Mondego, na difusão e comércio das campanienses na zona sudoeste da Península Ibérica.

\section{A COLECÇÃO DO MUSEU REGIONAL DE SINTRA}

As peças do Museu Regional de Sintra, inventariadas sob a designação de "cerâmica campaniense" e de "imitação de cerâmica campaniense", perfazem um total de 23 fragmentos, tendo 5 delas sido publicadas por M. MAIA, em 1987, na sua tese de doutoramento $\left({ }^{7}\right)$ -

(7) M. MAIA, 1987, voi. 2, pp. 60-65 e Ests. n. ${ }^{\circ}$ III, IV e V.

Conimbriga, 35 (1996) 37-58 
números 1,2, 11, 13 e 19 do Catálogo - e correspondendo, por sua vez, a 4 fragmentos de cerâmica campaniense B e a 1 de imitação de campaniense $\mathrm{B}$, este último naquela tese descrito incorrectamente como sendo de campaniense B. Sabemos ainda da "existência ?" de um outro fragmento campaniense exumado no concelho de Sintra, mais concretamente no Casal do Silvério (freg. de Almargem do Bispo) $\left(^{8}\right)$, o qual, por não se encontrar conservado no Museu Regional e não se saber actualmente do seu paradeiro, a fim de o mesmo poder ser convenientemente estudado, se encontra excluido do presente trabalho. Sobre este último fragmento, R ROUILLARD $\left({ }^{9}\right)$ levanta sérias dúvidas de se tratar de uma peça em cerâmica campaniense "verdadeira", pelo que pensamos estar perante uma imitação de campaniense, ou, então, na presença de uma simples peça de cerâmica comum.

Achámos pertinente englobar neste artigo todo o conjunto constituído pelas cerâmicas campanienses e de imitação de campaniense sintrenses, não só pelo mesmo possuir grande homogeneidade nas formas (tipologia clássica), como também por apresentar as características gerais peculiares e essenciais atribuíveis aos fabricos daquelas cerâmicas pastas muito depuradas, engobes negros e brilhantes e pés em anel. Recorde-se ainda que, ceramológica e cronologicamente, as ilações deduzíveis das peças de imitação são de grande importância histórico-arqueológica, confundindo-se, assim, o seu contributo com o das peças consideradas "verdadeiras".

No nosso caso, a dedução das peças de imitação de campaniense teve em conta a detecção, quase sempre, de cerâmicas propriamente campanienses nas villae onde foram exumadas, embora tal não fosse, de modo algum, obrigatório para a sua identificação. De facto, entre quase todas as estações analisadas e que forneceram cerâmicas campanienses [4 em 5: Armez, Ermidas, São Marcos e São Miguel de Odrinhas - ficando apenas de fora a Granja dos Serrões por somente ter fornecido um fragmento de cerâmica campaniense -, as quais correspondem a metade do total das estações concelhias], foram igualmente recolhidos fragmentos de imitação de campaniense, o mesmo não sendo possível dizer, infelizmente, em sentido inverso [3 em $8(=37,5 \%$ do total das estações de Sintra): Casal de Pianos - Pombal, Funchal e Lugar do Marcador].

$\left.{ }^{8}\right)$ O. da Veiga Ferreira, 1971, pp. 315, 319 e 320; J. Cardim Ribeiro, 1982-83 , p. 425 , nota 3 .

(9) P. Rouillard, 1993, p. 57. 
De qualquer dos modos, e nesta análise concreta, a maior parte das peças de imitação de campaniense estudadas pertencem às estações que forneceram igualmente cerâmicas campanienses "verdadeiras", perfazendo um conjunto de 11 fragmentos $(=73 \%)$ num total de 15 exemplares, contra apenas 4 fragmentos $(=27 \%$ do total), atribuídos às estações que apenas forneceram cerâmicas de imitação de campaniense.

Todos os fragmentos da colecção ora em análise - entre peças de cerâmicas campanienses e de imitação -, provêm, na sua totalidade, de villae implantadas na área geográfica do actual concelho de Sintra. Temos assim: 8 peças recolhidas em Armez (freg. da Terrugem) [ $=35 \%$ da colecção] e relativas a prospecções de superfície, efectuadas em terrenos próximos da Fonte Romana; 2 fragmentos exumados em Casal de Pianos - Pombal (freg. de São João das Lampas) [=9\% da colecção] e correspondentes a achados de superfície; 3 exemplares provenientes de Ermidas (freg. de São João das Lampas) [=13\% da colecção] e obtidos em prospecções; 1 fragmento detectado no Funchal (freg. de São João das Lampas) $[=4 \%$ da Colecção], igualmente originário de recolhas superficiais; 1 peça achada no lugar do Marcador, à superfície (freg. de São Martinho) [ $=4 \%$ da colecção]; 3 fragmentos encontrados em São Marcos (freg. de Agualva-Cacém) [=13\% da colecção] e atribuídos à campanha de escavações de 1979; 4 outros fornecidos pela campanha de escavações de 1957 levada a efeito em São Miguel de Odrinhas por D. Fernando de Almeida (freg. de São João das Lampas) $[=18 \%$ da colecção]; e 1 peça recolhida na Granja dos Serrões (freg. de Almargem do Bispo), na campanha de escavações de 1995 [=4\% do total].

Dos 23 fragmentos estudados, apenas 8 (=35\% do total) correspondem a cerâmicas propriamente campanienses, contra uma maioria de 15 peças $(=65 \%$ do total), correspondentes a exemplares de imitação. Dentro do primeiro grupo - cerâmicas campanienses -, não se observaram quaisquer registos de peças atribuíveis à classe $\mathrm{C}$ de $\mathrm{N}$. LAMBOGLIA, pertencendo às classes $A$ ( 1 peça $)$ e $B(7$ peças $)$ todos os exemplares examinados.

No que concerne ao grupo das peças de imitação de campaniense, somente em 9 fragmentos $(=60 \%)$ nos foi possível discernir qual a forma ou a classe imitada, contra 6 exemplares $(=40 \%)$ em que não se pode adiantar essas características. No primeiro grupo, 2 achados são em imitação de campaniense B (=13\% - peças n. ${ }^{\circ} 1$ e 15 do catálogo), 2 em imitação de campaniense $C\left(=13 \%\right.$ - peças n. ${ }^{\circ} 6$ e 9 do catálogo), e apenas 1 em imitação de campaniense $\mathrm{A}(=7 \%$ - peça 
n. ${ }^{\circ} 8$ do catálogo), englobando as restantes (peças n. ${ }^{\circ} 3,4,7,14,16$, 18,20 e 22 do catálogo) um grupo apenas designado por "cerâmicas de imitação de campaniense", unicamente detentoras de pastas e engobes aparentados com os das campanienses consideradas "verdadeiras".

Se somarmos os 7 fragmentos de cerâmica campaniense B (=30\% da colecção - peças n. ${ }^{\circ} 2,11,13,16,17,19$ e 20 do catálogo) aos 2 outros $\left(=9 \%\right.$ - peças n. ${ }^{\circ} 1$ e 15 do catálogo), em que se denotou imitarem o reportório das formas características daquela classe [contra $1(=4 \%$ peça n. $^{\circ} 23$ do catálogo) de campaniense A; $2\left(=9 \%\right.$ - peças n. ${ }^{\circ} 6$ e 9 do catálogo) de imitação de campaniense $\mathrm{C}$; e $1\left(=4 \%\right.$ - peça $\mathrm{n}^{\circ} 8$ do catálogo) de imitação de campaniense A], obtemos um significativo subconjunto de 9 peças ( $=39 \%$ do total da colecção) detentor de grandes afinidades produtivas. Julgamos que a este grupo pertencerão, certamente, muitos outros fragmentos objecto do nosso trabalho e apenas identificados como exemplares de imitação de campaniense. Este facto fornece uma certa homogeneidade à colecção sintriana, podendo ser-lhes atribuída, ainda que sob reservas, algumas das características e cronologias comuns às cerâmicas campanienses B de N. LAMBOGLIA.

\section{1 - Formas}

Para a análise das peças do Museu Regional de Sintra, optámos pela classificação de N. LAMBOGLIA quanto às classes dos fabricos das cerâmicas campanienses (comummente aceite), e pelo repertório formal de Jean-Paul MOREL, por ser este, de longe, o mais completo e exaustivo dentro daqueles tipos cerâmicos. De salientar, ainda, o facto deste último ceramologo incluir na sua tipologia as cerâmicas de vemiz negro e pastas depuradas, mas de nítida imitação das campanienses "oficiais".

Da totalidade da colecção, apenas em 8 exemplares $(=35 \%$ peças $\mathrm{n}^{\circ} 3,4,7,14,16,18,20$ e 22 do catálogo) não se tornou viável adiantar ou sugerir uma forma aproximada. Os fragmentos que investigámos possuem, na generalidade, reduzidas dimensões, o que dificulta sobremaneira a detecção da respectiva forma. Por isso, fomos obrigados a alargar o seu espectro formal, o que levou, logicamente, à impossibilidade de obtermos certezas ou cronologias mais precisas. Optou-se, em primeiro lugar, por procurar a forma global que melhor se coadunasse a cada peça [conseguida isoladamente em 8 casos 
$(=35 \%)$ - peças n. ${ }^{\circ} 5,6,9,10,13,17,19$ e 21 do catálogo], inscrevendo-se, em segundo lugar, a análise dos pés cerâmicos [conseguida isoladamente em 5 casos $(=22 \%)$ - peças $n .^{\circ} 2,11,12,15$ e 23 do catálogo], tendo-se apenas registado 2 únicas situações onde nos foi permitido obter formas para a peça e para o respectivo pé $(=9 \%)$ - fragmentos $n{ }^{\circ}$ 1 e 8 do catálogo).

Não se pode afirmar que existe uma preponderância deste ou daquele tipo de forma dentro do universo tipológico de Jean-Paul MOREL, dado nenhum se repetir, pelo que nos escusamos de apresentar percentagens dos mesmos. Nota-se, isso sim, uma ligeira predominância das páteras e taças, em detrimento de outras formas utilitárias.

Embora de um modo geral a colecção de Sintra apresente características tipológicas e/ou ceramológicas atribuíveis ao fabricos tradicionais da campaniense $\mathrm{B}$, registaram-se, contudo, alguns casos notórios de fabricos diferentes ou, então, aparentados com os de outras classes da campaniense - peça n. ${ }^{\circ} 23$, classificada como campaniense A; peça.$^{\circ} 8$, classificada como imitação de campaniense A e peças $n .^{\circ}$ 6 e 9 , classificadas como imitação de campaniense C.

No primeiro caso, peça $\mathrm{n}^{\circ} 8$, colocamos muitas reservas quanto à atribuição de uma forma concreta dentro da tipologia de Jean-Paul MOREL, dado não se ter detectado um paralelo preciso. Nos restantes casos (peças n. ${ }^{\circ} 23,6$ e 9), pensamos ter uma margem de erro menor.

\section{2 - Cronologia}

Podemos apontar como principais balizas cronológicas da colecção sintriana o século III a. C., para as mais antigas, e os anos 50/30 a. C. (limite dos fabricos de cerâmica campaniense B), para as mais recentes.

Contudo, é nos séculos II e I a. C. que se deve encontrar a datação correcta da colecção, correspondendo esta cronologia, por seu lado, à "predominância" dos fabricos de campaniense B e consequentes imitações.

A peça com cronologia mais recuada de todo o conjunto consiste num fundo em imitação de campaniense, com um pé em anel observável no tipo 5726 al de MOREL, proveniente da villa de Ermidas e que aponta para os inícios do século III a. C. (cerca de 300 a. C.). Ressalve-se, neste caso específico, a inexistência de um paralelo exacto para o pé da peça em questão, pelo que apresentamos aqui esta datação

Conimbriga, 35 (1996) 37-58 
como a hipótese mais plausível. Pensamos, porém, e tendo em conta o contexto temporal da maior parte das peças campanienses e de imitação do Museu Regional de Sintra, ser possível fazer-se avançar a datação do fragmento n. ${ }^{\circ} 12$ até níveis médios ou finais daquela centúria.

Há que lembrar a este propósito que a villa de Ermidas constitui uma das quatro estações estudadas que forneceu cerâmicas campanienses B, tendo-se registado nestas a existência de um fragmento datado com rigor do século I a. C. (90 a. C. \pm 50 anos - peça n. ${ }^{\circ} 11$ do catálogo) e de um outro, atribuído com segurança aos finais do século II a. C. (peça n. ${ }^{\circ} 13$ do catálogo), os quais vêm, de certo modo, aproximar o intervalo entre os vários fabricos e atestar uma ocupação contínua da villa, durante aquelas três centúrias.

A segunda peça datada do século III a. C. (inícios/meados) é o fragmento n. ${ }^{\circ}$ 17, proveniente da campanha de escavações de 1979 efectuada na villa de São Marcos e relativo a um fundo de campaniense B com pé em anel incipiente, quase imperceptível. Nesta estação, foi igualmente encontrado um outro fragmento de cerâmica campaniense $\mathrm{B}$ (peça n. $^{\circ} 16$ do Catálogo), cuja forma, infelizmente, nos é impossível determinar. Para aquele exemplar, poder-se-á dizer o mesmo que se observou para a peça $n .^{\circ} 12$, isto é, que a sua datação poderá ser avançada até níveis mais recentes dentro do século III a. C. (finais).

Nas villae que forneceram as únicas peças datáveis do século III a. C., foram igualmente detectados outros tipos cerâmicos, atribuíveis a níveis antigos de ocupação romana. Temos, assim, verificada a existência de cerâmicas de transporte de nítido fabrico neopùnico, em São Marcos $\left({ }^{10}\right)$, e de ânforas de segura datação anterior ao século II a. C., em ambas as estações (Ermidas e São Marcos), embora estas sejam

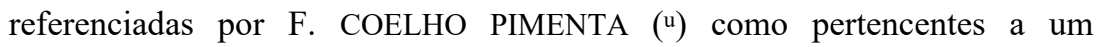
fabrico "extra-peninsular e/ou controverso?". No caso da estação de São Marcos, foram ainda recolhidas mós em forma de sela entre os estratos romanos (actualmente expostas no Museu Regional), que nos sugerem datações certamente anteriores ao século II a. C. para aqueles níveis.

Apenas foi detectado um único fragmento de campaniense $\mathrm{A}$ [(peça n. ${ }^{\circ} 23$ do catálogo), o qual ostenta um pé algo similar com o classificado por Morei sob o n. ${ }^{\circ} 11$ e, de certo modo, também, com o pé patente no seu tipo $253 \mathrm{al}$, cuja data aponta para o intervalo situado

${ }^{(10)}$ F. Coelho Pimenta, 1982-83, pp. 117-150.

(n) Id., ib.. 
entre os meados do século II a. C. e os meados da centúria seguinte] e um exemplar que nos parece ser de imitação de campaniense A [(peça n. ${ }^{\circ} 8$ do catálogo), o qual apresenta uma forma atribuível, ainda que sob reservas, ao Tipo 2152 al de MOREL, e um pé, observável no Tipo 2154 cl também de MOREL e datável, grosso modo, do primeiro quartel do século II a. C], atestando a raridade destes fabricos nestas áreas peninsulares.

\section{OBSERVAÇÃO FINAL}

A data de 218 a. C., aceite como a da chegada das tropas de Cneu Cipião à Península Ibérica e, de resto, comprovada pelas fontes clássicas, não pode, em nosso entender, marcar o início da "romanização" da Península, mas tão só o início da conquista militar desta, dado que já muito antes dos finais do século III a. C. se vinham verificando contactos massivos entre os autóctones peninsulares e aquela civilização.

Estas ligações, comerciais e não só, são comprovadas pela existência de cerâmicas romanas de grande qualidade e em quantidades surpreendentes, as quais atestam a grande influência da civilização e cultura romanas na Península Ibérica desde períodos remotos.

A descoberta de achados cerâmicos romanos e de outros ostentando imitações de formas características das produções itálicas anteriores aos finais do século III a. C. denuncia, para além da simples transação comercial a si inerente, a grande proximidade existente entre as duas penínsulas (Itálica e Ibérica), observável a níveis tão diversos como o económico, o comercial, o artístico, o religioso e o material.

No caso específico da zona $\mathrm{W}$ do municipium Olisiponense, e a ter em conta as cronologias aferidas neste artigo, achamos dever rever-se as datações, geralmente e desde há muito apontadas para os inícios da "romanização" desta região ou, melhor, para a "presença" romana nesta área geográfica, propondo-se, desde já, o recuo dessa cronologia até níveis plenos do século III a. C.

\section{CATÁlOGO:}

N. 1 - MRS/AR/R/85/1 (Est. I, n. ${ }^{\circ}$ 1); fragmento de fundo de pátera com pé em anel em imitação de campaniense B. M. MAIA (1987, voi. 2, p. 63) 
insere, por lapso, esta peça no seu conjunto de campaniense B. Trata-se, sem dúvida alguma, de uma peça de imitação.

Forma: Tipo 2272 bl de Morei. Pé Tipo 178 dl de Morel (cfr. M. MAIA, 1987, voi. 2, p. 63).

Diâmetro: $72 \mathrm{~mm}$ (a nível do limite externo do pé em anel).

Pasta: castanha-acinzentada, de tom escuro, com manchas de cozedura, dura, pouco porosa, de fractura não rectilínea, micácea, com elementos não plásticos de pequenas e médias dimensões.

Engobe: externo/negro, micáceo, espesso, sem brilho, homogéneo; interno/idêntico ao externo.

Cronologia: primeira metade do século I a. C.

Proveniência: villa de Armez, superfície.

N. ${ }^{\circ} 2$ - MRS/AR/R/85/2 (Est. I, n. ${ }^{\circ}$ 2); fragmento de fundo com pé em anel de pátera em campaniense $\mathrm{B}$.

Forma: indeterminável. Pé Tipo 145 al de Morel (cfr. M. MAIA, 1987, voi. 2 , pp. 60 e 61$)$.

Diâmetro: $97 \mathrm{~mm}$ (ao nível do limite externo do pé em anel).

Pasta: beige-acastanhada, de tom escuro, dura, muito porosa, de fractura não rectilínea, com elementos não plásticos de pequenas dimensões.

Engobe: externo/negro-acastanhado muito escuro, pouco espesso, homogéneo, brilhante; interno/idêntico ao externo.

Decoração: possui uma canelura pouco profunda ao nível do fundo interno.

Cronologia: segunda metade do século II a. C., com incidência no último quartel. M. MAIA (1987, p. 60) adianta ainda, e com base em datações de paralelos ibéricos, uma cronologia alargada até à primeira metade do século I a. C.

Proveniência: villa de Armez, superfície.

N. 3 - MRS/AR/R/86/14; fragmento de parede de taça em imitação de campaniense.

Forma: indeterminável.

Pasta: beige-acastanhada, de tom vivo, dura, de grão fino, porosa, de fractura não rectilínea, com materiais não plásticos de pequeníssimas dimensões.

Engobe: inexistente.

Cronologia: provavelmente os séculos II-I a. C.

Proveniência: villa de Armez, superfície.

N. ${ }^{\circ} 4$ - MRS/AR/R/86/15; fragmento de fundo de taça em imitação de campaniense.

Forma: indeterminável.

Conimbriga, 35 (1996) 37-58 
Pasta: cinzenta, não muito escura, de grão muito fino, dura, porosa, de fractura não rectilínea, micácea, com materiais não plásticos de pequeníssimas dimensões.

Engobe: inexistente.

Cronologia: provavelmente os séculos II-I a. C.

Proveniência: villa de Armez, superfície.

N. 5 - MRS/AR/R/86/16 (Est. I, n. ${ }^{\circ} 3$ ); fragmento de bordo de taça em imitação de campaniense.

Forma: Tipo 2865 bl de Morei.

Diâmetro: $188 \mathrm{~mm}$ (ao nível do extremo exterior do bordo).

Pasta: cinzenta escura, fina, dura, micácea, porosa, de fractura não rectilínea, com materiais não plásticos de médias dimensões.

Engobe: inexistente.

Cronologia: século I a. C.

Proveniência: villa de Armez, superfície.

N. 6 - MRS/AR/R/86/174 (Est. I, n. ${ }^{\circ} 4$ ); fragmento de fundo de taça em imitação de campaniense $\mathrm{C}$.

Forma: Tipo 2156 al de Morei.

Pasta: cinzenta-acastanhada, pouco porosa, dura, de fractura não rectilínea e cortante, com materiais não plásticos de pequenas dimensões.

Engobe: tipo aguada; externo/negro, espesso, sem brilho; interno/ /idêntico ao externo.

Cronologia: primeira metade do século II a. C.

Proveniência: villa de Armez, superfície.

N. 7 - MRS/AR/R/86/378; fragmento de parede de taça em imitação de campaniense.

Forma: indeterminável.

Pasta: cinzenta-acastanhada escura, dura, de fractura não rectilínea, porosa com materiais não plásticos de pequenas dimensões.

Engobe: externo/negro, espesso, brilhante; interno/inexistente.

Cronologia: provavelmente os séculos II-I a. C.

Proveniência: villa de Armez, superfície.

N. 8 - MRS/AR/R/88/52 (Est. I, n. ${ }^{\circ}$ 5); fragmento de parede e fundo de taça com pé em anel em imitação de campaniense A.

Forma: Não encontrámos paralelos exactos para esta forma. Talvez se possa adiantar o tipo 2152 al para a inclinação da parede do taça e o tipo 2154 cl para o pé, como os mais aproximados dentro do repertório de Jean-Paul Morei.

Conimbriga, 35 (1996) 37-58 
Diâmetro: $68 \mathrm{~mm}$ (ao nível do extremo exterior do anel).

Pasta: cinzenta escura, fina, micácea, porosa, dura, de fractura não rectilínea, com materiais não plásticos de médias dimensões.

Engobe: inexistente.

Cronologia: cerca de 200 a. C./primeiro quartel do século II a. C. para a forma da parede e cerca de 190 a. C. \pm 30 anos para o pé.

Proveniência: villa de Armez, superfície.

N. 9 - MRS/CPP/R/81/27 (Est. II, n. ${ }^{\circ} 6$ ); fundo inteiro com pé em anel de pequenina taça em imitação de campaniense $\mathrm{C}$.

Forma: Tipos $1253 \mathrm{bl} ; 1253 \mathrm{cl}$ de Morei.

Diâmetro: 36 mm (ao nível do limite exterior do pé em anel).

Pasta: cinzenta escura, de grão fino, dura, pouco porosa, de fractura algo rectilínea, com materiais não plásticos de pequenas dimensões.

Engobe: externo/cinzento acastanhado, de tom escuro, pouco espesso, homogéneo, sem brilho; interno/inexistente.

Cronologia: séculos II-I a. C.

Proveniência: villa de Casal de Pianos (Pombal), Quadrado 3, I ${ }^{\mathrm{a}}$ camada.

N. ${ }^{\circ} 10$ - MRS/CPP/R/81/36 (Est. II, n. ${ }^{\circ} 7$ ); fragmento de bordo de pequena taça em imitação de campaniense.

Forma: Tipo 2615 bl de Morei.

Pasta: cinzenta escura, fina, dura, micácea, de fractura não rectilínea, porosa, com elementos não plásticos de pequenas dimensões.

Engobe: tipo aguada; externo/cinzento muito escuro quase negro, espesso, sem brilho; interno/idêntico ao externo.

Cronologia: meados do século II a. C.

Proveniência: villa de Casal de Pianos (Pombal), quadrado 3, I ${ }^{a}$ camada.

N. ${ }^{\circ} 11-\mathrm{MRS} / \mathrm{ED} / \mathrm{R} / 83 / 1$ (Est. II, n. ${ }^{\circ} 8$ ); fragmento de fundo com pé em anel de pátera em campaniense $\mathrm{B}$.

Forma: Tipo 253 al de Morei para o pé (cfr. M. MAIA, 1987, voi. 2, pp. 64 e 65$)$.

Diâmetro: 99 mm (ao nível do limite exterior do pé em anel).

Pasta: beige-acastanhada, de tom algo rosado, dura, pouco porosa, de grão fino, de fractura não rectilínea.

Engobe: externo/negro acastanhado, não homogéneo, pouco espesso, brilhante; interno/idêntico ao externo, mas menos brilhante.

Cronologia: 90 a. C. \pm 40 anos.

Proveniência: villa de Ermidas, superfície. 
N. 12 - MRS/ED/R/83/49 (Est. II, n. ${ }^{\circ}$ 9); fragmento de fundo com pé em anel de pequeno jarro em imitação de campaniense.

Forma: Tipo 5726 al de Morel? Este tipo é o que apresenta a forma mais aproximada do pé em análise.

Diâmetro: $55 \mathrm{~mm}$ (ao nível do limite externo do pé em anel).

Pasta: castanha-acinzentada, dura, pouco porosa, de fractura não rectilínea.

Engobe: externo/negro, espesso, homogéneo, sem brilho; interno/ /idêntico ao externo.

Cronologia: cerca de 300 a. C. Julgamos, pelo contexto das peças restantes da colecção do Museu Regional de Sintra, poder estender esta cronologia a níveis do século III a. C. Esta peça consiste, ainda assim, numa das mais antigas da colecção.

Proveniência: villa de Ermidas, superfície.

N. 13 - MRS/ED/R/84/1 (Est. II, n. ${ }^{\circ} 10$ ); fragmento de aba e parede de pátera em campaniense $\mathrm{B}$.

Forma: Tipo 2272 bl de Morel (cfr. M. MAIA, 1987, voi. 2, p. 62).

Pasta: beige-acastanhada, dura, de grão, fino, porosa, de fractura rectilínea, com materiais não plásticos de pequenas dimensões.

Engobe: externo/negro acastanhado, pouco espesso, homogéneo, brilhante; interno/idêntico ao externo.

Cronologia: finais do século II a. C. ou o século I a. C.

Proveniência: villa de Ermidas, superfície.

N. 14 - MRS/FU/R/83/159 ; fragmento de parede de taça em imitação de campaniense. Fundo?

Forma: indeterminável.

Pasta: cinzenta clara, de grão fino, dura, porosa, de fractura não rectilínea, com materiais não plásticos de médias dimensões.

Engobe: externo/inexistente; interno/negro, não muito escuro, pouco espesso, sem brilho.

Cronologia: provavelmente os séculos II-I a. C.

Proveniência: villa do Funchal, superfície.

N. ${ }^{\circ} 15$ - MRS/LM/R/77/67 (Est. II, n. ${ }^{\circ} 11$ ); fragmento de fundo com pé em anel de pátera em imitação de campaniense B.

Forma: Tipo 172 a2 de Morei para o pé em anel.

Diâmetro: $57 \mathrm{~mm}$ (ao nível do limite exterior do pé em anel).

Pasta: cinzenta escura, dura, pouco porosa, micácea, de fractura não rectilínea, com elementos não plásticos de pequenas e médias dimensões.

Engobe: tipo aguada; externo/cinzento escuro do mesmo tom da pasta, espesso, brilhante; interno/idêntico ao externo.

Conimbriga, 35 (1996) 37-58 
Marcas : a peça em análise possui uma marca esgrafitada no fundo externo, junto ao arranque do pé em anel, composta por um nexo de duas letras - TA.

Cronologia: meados ou á $2^{\text {a }}$ metade do século II a. C.

Proveniência: villa do Lugar do Marcador, superfície.

N. ${ }^{\circ} 16$ - MRS/SM/R/79/7; fragmento de fundo de pátera em campaniense B.

Forma: indeterminável.

Pasta: beige-acastanhada, de tom rosado, dura, porosa, de grão fino, porosa, de fractura não rectilínea, com elementos não plásticos de médias dimensões.

Engobe: externo/negro, pouco espesso, homogéneo, muito brilhante; interno/idêntico ao externo.

Cronologia: entre os inícios/meados do século II a. C. e 50/30 a. C.

Proveniência: villa de São Marcos, escavações de 1979, superfície.

N. ${ }^{\circ} 17$ - MRS/SM/R/79/119 (Est. II, n. ${ }^{\circ}$ 12); fragmento de fundo de taça (prato?) com pé em "anel” algo estilizado em campaniense B.

Forma: Espécie 2140 de Morei. Confrontar também espécie 2500 de Morei, tipos 2512 bl e 2513 al.

Diâmetro: $161 \mathrm{~mm}$ (ao nível do limite exterior do pé em “anel”).

Pasta: beige-acastanhada, de tom escuro e rosado, dura, porosa, de fractura rectilínea, com elementos não plásticos de pequenas dimensões.

Engobe: externo/apenas denotado a nível de vestígios nos ressaltos exteriores do pé; acastanhado muito escuro, de tom avermelhado correspondente a manchas de cozedura ou de empilhamento, pouco espesso, pouco brilhante; i nterno/inexi stente.

Cronologia: inícios do século III a. C. para a espécie 2140 de Morei.

Proveniência: villa de São Marcos, escavações de 1979, 3ª camada.

N. 18 - MRS/SM/R/79/167; fragmento de pé em anel de pequena taça em imitação de campaniense.

Forma: indeterminável.

Pasta: cinzenta algo escura, dura, muito porosa, de fractura não rectilínea, com materiais não plásticos de pequenas e médias dimensões.

Engobe: inexistente.

Cronologia: provavelmente os séculos II-I a. C.

Proveniência: villa de São Marcos, escavações de 1979, 4ª camada.

N. ${ }^{\circ} 19$ - MRS/SM/R/79/156 (Est. II, n. ${ }^{\circ} 13$ ); fragmento de bordo e parede de taça em campaniense $\mathrm{B}$.

Forma: Tipo 2321 bl de Morel (cfr. M. MAIA, 1987, voi. 2, p. 64). 
Diámetro: $128 \mathrm{~mm}$ (ao nivel do limite externo do bordo).

Pasta: beige-acastanhada escura, de torn rosado, dura, porosa, de fractura rectilínea, com materiais não plásticos de pequenas dimensões.

Engobe: externo/negro-acastanhado, pouco espesso, não homogéneo, brilhante, com reflexos; interno/idêntico ao externo, mas homogéneo.

Cronologia: século I a. C.

Proveniência: villa de São Marcos, escavações de 1979, 2a camada.

N. 20 - $\mathrm{MRS} / \mathrm{SMO} / \mathrm{R} / 57 / 1$; fragmento de parede lateral de taça em campaniense B.

Forma: indeterminável.

Pasta: castanha escura, algo rosada, de grão fino, dura, pouco porosa, de fractura não rectilínea, com materiais não plásticos de pequenas dimensões.

Engobe: externo/negro, espesso, homogéneo, muito brilhante; interno/ /idêntico ao externo.

Cronologia: entre os inícios/meados do século II a. C. e 50/30 a. C.

Proveniência: villa de São Miguel de Odrinhas, escavações de 1957.

N. 21 - MRS/SMO/R/57/133 (Est. II, n. ${ }^{\circ}$ 14); fragmento de bordo de pequena taça em imitação de campaniense.

Forma: Tipo 1643 al de Morei, como a mais aproximada do repertório.

Diâmetro: $121 \mathrm{~mm}$ (ao nível do extremo exterior do bordo).

Pasta: cinzenta escura, de grão muito fino, dura, micácea, porosa, de fractura rectilínea, com materiais não plásticos de pequenas e médias dimensões.

Engobe: inexistente.

Cronologia: cerca de 220 a. C. \pm 30 anos. Esta datação abrange a última década do século II a. C., devendo encontrar-se aqui, em nossa opinião, a cronologia mais adequada para o fabrico da peça em análise.

Proveniência: villa de São Miguel de Odrinhas, escavações de 1957.

N. ${ }^{\circ} 22$ - MRS/SMO/R/57/56; fragmento de parede carenada de taça em imitação de campaniense.

Forma: indeterminável.

Pasta: cinzenta escura, de grão médio, dura, micácea, porosa, de fractura não rectilínea, com materiais não plásticos de pequenas e médias dimensões.

Engobe: externo/negro, pouco espesso, brilhante; interno/idêntico ao externo, mas sem brilho.

Cronologia: séculos II-I a. C.

Proveniência: villa de São Miguel de Odrinhas, escavações de 1957.

N. ${ }^{\circ} 23$ - MRS/GS/95/III/[ 1 ] (Est. II, n. ${ }^{\circ}$ 15); fragmento de fundo de pequena taça com pé em anel esvasado para o exterior em campaniense A.

Conimbriga, 35 (1996) 37-58 
Forma: pé n. ${ }^{\circ} 11$ de Morel, como o mais aproximado, dado não se ter detectado nenhum paralelo exacto. Cfr. ainda o pé inventariado sob o n. ${ }^{\circ} 253$ al, igualmente de Morei; o pé em anel da forma Tipo 1240 a 1 e o patente na forma Tipo 2245 al também de J.-P. Morel.

Diâmetro: $60 \mathrm{~mm}$ (ao nível exterior do pé em anel).

Pasta: vermelha-acastanhada escura, de tom algo vivo, muito depurada, porosa, dura, mal cozida, com elementos não plásticos de pequenas dimensões, de fractura irregular.

Engobe: externo/negro muito escuro, com manchas não homogéneas de cozedura e laivos avermelhados de empilhamento, pouco espesso, brilhante; interno/idêntico ao externo.

Cronologia: datação localizada entre os meados do século II a. C. e os meados da centúria seguinte.

Proveniência: villa da Granja dos Serrões, campanha 2, 1995, detectado junto à sepultura VI.

\section{BIBLIOGRAFIA}

AlarCão, J., 1988, Roman Portugal, fases. I, II e III.

—, 1990, Nova História de Portugal, vol. I, "Portugal. Das Origens à Romanização", $I^{a}$ edição, Ed. Presença.

ARRUDA, A., 1986, "Castro Marim na Idade do Ferro", Actas do IV Congresso do Algarve, I, pp. 401-406.

Boube, J., 1985-1986, "Introduction a l'Étude de la Céramique à Vernis Noir de Sala" Bulletin d'Archéologie Marocaine, tomo XVI, pp. 121-190.

Brochado de Almeida, C. A., 1990, Proto-História e Romanização da Bacia Inferior do Lima, Viana do Castelo.

CARdim Ribeiro, J., 1982-83, "Estudos histórico-epigráficos em torno da figura de $L$. Iulius Maelo CaudicuV| Sintria, vol. I-II, p. 425, nota 3.

Coelho Pimenta, F., 1982-83, "Subsídios para o estudo do material anfórico conservado no Museu Regional de Sintra", Sintria, pp. 117-150.

Clariana I Roig, J. F., 1990, "La Ceràmica de Vemis Negre”, Laietania, 5, pp. 49-51.

CURA Y Morera, 1985, "Les Ceràmiques de Vernis Negre de Can Sotaterra a Solsona i F estratigrafía comparada dels jaciments pre-romans del Solsonès", Faventia, 7/2, pp. 105-113.

Delgado, M., 1971, "Cerâmica Campaniense em Portugal", Actas do II Congresso Nacional de Arqueologia, Coimbra, pp. 403-420.

----, 1976, "Céramiques Campaniennes et de Type Campanien", Fouilles de Conimbriga, VI, pp. 21-26 e PI. IV.

Dias Diogo, A. M., 1979, "O Material Romano da Ia Campanha de Escavações na Alcáçova de Santarém", Conimbriga, XXIII, pp. 111-141.

Dias Diogo, A. M. e CARdoso, J. P., 1992, "Cerâmica Campaniense Proveniente da Foz do Arade (Portimão)", Artefactos, vol. I, pp. 9-11.

Conimbriga, 35 (1996) 37-58 
Ferreira da Silva, A. C., 1986, A Cultura Castreja no Noroeste de Portugal, Paços de Ferreira.

Hidalgo Cuñarro, J. M. e Viñas Cue, R., 1992-93 "Nuevas Cerámicas Romanas de Importación del Castro de Vigo (Campaña de 1987)”, Cástrelos, 5-6, pp. 41-70.

Lamboglia, N., 1952, "Per una Classificazione Preliminare della Ceramica Campana", Atti del I Congresso Internazionale di Studi Liguri, Bordighera, pp. 139-206.

---, 1954, "Polemiche Campane", Rivista di Studi Liguri, XXVI, 1-4, pp. 292-304.

LlORIS, M. B., 1990, Guía de la Ceràmica Romana, Saragoça, pp. 39-60.

Maia, M., 1987, Romanização do Territòrio Hoje Português a Sul do Tejo, voi. 2, Lisboa, pp. 52-83.

Melim de Sousa, E. e SePúlveda, E., "A propòsito de três peças republicanas de Tróia de Setúbal", a publicar.

Morel, J. P., 1981, Céramique Campanienne: Les Formes, Roma.

Pérez Ballester, J., 1986, "Las Cerámicas de Barniz Negro, 'Campanienses': Estado de la Cuestión", Boletín del Museo Arqueológico Nacional, tomo IV, n. ${ }^{\circ}$ 1, pp. 27-45.

Ponte, S. da, 1988, Villa Rústica de São Pedro de Caldeias - Tomar, pp. 81 e 82.

Prados Torreira, L. e Santos Velasco, J. A., 1984, "La Colección Ceramica Campaniense de Ibiza en el Museo Arqueológico Nacional", Lucentum, III, pp. 67-77.

Rouillard, P., com a colaboração de J.-J. JULly, 1993, "Hispanie Préromaine/1. Phéniciens, Grecs, Étrusques et Puniques/1968-1972", Histoire et Archéologie de la Péninsule Ibérique. Chroniques Quinquennales, 1968-1987, p. 57.

Soares, J. e Tavares da Silva, C., 1973, "Ocupação do Período Proto-Romano do Povoado do Pedrão (Setúbal)", Actas das II Jornadas Arqueológicas da Associação dos Arqueólogos Portugueses, Lisboa, pp. 245-306.

SoARes, J., 1978, "Nótula sobre a Cerâmica Campaniense do Castelo de Alcácer do Sal", Setúbal Arqueológica, IV, pp. 133-144.

TaVAReS DA Silva, C., 1978, "Ocupação da II Idade do Ferro da Pedra da Atalaia (Santiago do Cacém)", Setúbal Arqueológica, 4, pp. 117-132.

Tavares da Silva e Soares, J., 1993, Ilha do Pessegueiro. Porto Romano da Costa Alentejana, pp. 178 e 187, nota 106.

Veiga FerReirA, O., 1971, "Cerâmica Negra de tipo grego encontrada em Portugal", Arqueologia e Historia, 2a Série, III, pp. 313-332.

Ventura Martinez, J. J., 1985, "La Cerámica Campaniense 'C' y Seudocampaniense de pasta gris en la Provincia de Sevilla", Lucentum, IV, pp. 125-132.

-, 1992, "Ceramica Campaniense en la Cordoba Romana", Anales de Arqueologia Cordobesa, 3, pp. 137-170. ***

* Agradecemos ao Dr. Eurico Sepúlveda, para além do desenho do «Mapa de Distribuição das Cerámicas Campanienses e/ou de Imitação em Portugal» apresentado neste artigo, as suas preciosas achegas sobre a temática analisada.

** Todos os desenhos das peças cerâmicas insertas no nosso artigo devem-se a Paulo Jorge Faustino, à excepção do apresentado sob o n. 23 do Catálogo (Est. II, n. ${ }^{\circ}$ 15), que se deve a Ana Isabel Neves.

Conimbriga, 35 (1996) 37-58 
Mapa de Distribuição das Cerâmicas Campanienses e/ou de Imitação em Portugal: 1 - Coto da Pena (Caminha); 2 - Cidade Velha de Santa Luzia (Viana do Castelo); 3 - Cividade de Lanheses (Viana do Castelo); 4 - Castro de Romariz (Santa Maria da Feira); 5 - Antanhol (Coimbra); 6 - Lomba do Canho (Arganil); 7 - Conimbriga 8 - São Pedro de Caldeias (Tomar); 9 - Chões de Alpompé (Santarém); 10 - Scallabis; 11 - Castro do Salvador (Cadaval); 12 - Porto Sabugueiro (Muge); 13 - Castelo de Arruda dos Vinhos (Arruda dos Vinhos); 14 - Olisipo; 15 - Armés (Sintra); 16 - Casal de Pianos - Pombal (Sintra); 17 - Casal do Silvério (Sintra); 18 - Ermidas (Sintra); 19 - Funchal (Sintra); 20 - Lugar do Marcador (Sintra); 21 - São Marcos (Sintra); 22 - São Miguel de Odrinhas; 23 - Granja dos Serrões (Sintra); 24 - Freiria (Cascais); 25 - Outeiro de Polima (Cascais); 26 - Miroiços (Cascais); 27 - Cacilhas (Almada); 28 - São Paulo (Almada); 29 - Almaraz (Almada); 30 - Castro da Rotura (Palmeia); 31 - Castro de Chibanes (Palmeia); 32 - Pedrão (Setúbal); 33 - Tróia de Setúbal (Grândola); 34 - Alcácer do Sal; 35 - Pedra da Atalaia (Santiago do Cacém); 36 - Mirobriga; 37 - Sines; 38 - Monte Molião (Lagos); 39 - Foz do Arade (Portimão); 40 - Ilhéu do Rosário (Silves); 41 - Rocha Branca (Portimão); 42 - Cerro da Vila (Loulé); 43 - Cerro do Cavaco (Tavira); 44 - Balsal 45 - Baesuris; 46 - Almodôvar; 47 - Cola (Ourique); 48 - Castro da Mesa dos Castelinhos (Ourique); 49 - Castelo do Manuel Galo (Mértola); 50 - Myrtilis; 51 - Villa Romana das Neves (Castro Verde); 52 - Castelinho dos Mouros (Castro Verde); 53 - Castelo das Juntas (Castro Verde); 54 - Castelo Velho do Cobres (Castro Verde); 55 - Castro da Mangancha (Aljustrel); 56 - Castelo Velho do Roxo (Aljustrel); 57 - D. Pedro (Beja); 58 - Pisões (Beja); 59 - Represas (Beja); 60 - Fax Iulia 61 - Beja a Pequena (Beja); 62 - Sirpens 63 - Castelo Velho de Safara; 64 - Castro da Azougada (Moura); 65 - Castro dos Ratinhos (Moura); 66 - Castelo da Lousa (Mourão); 67 - Veiros (Estremoz); 68 - Castro de Segóvia (Eivas); 69 - Cabeça de Vaiamonte (Monforte). 


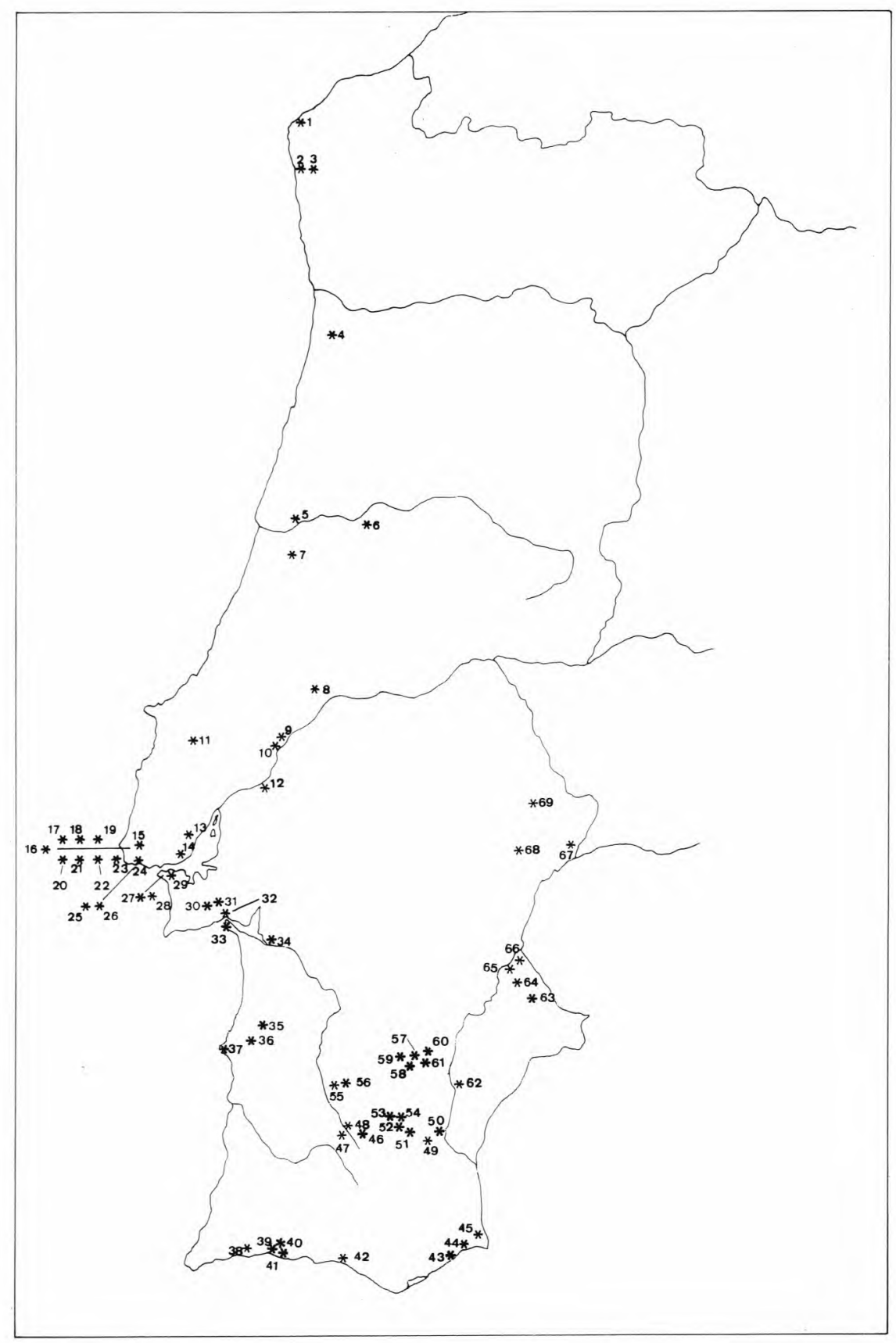

FIG. 1 
EST. I
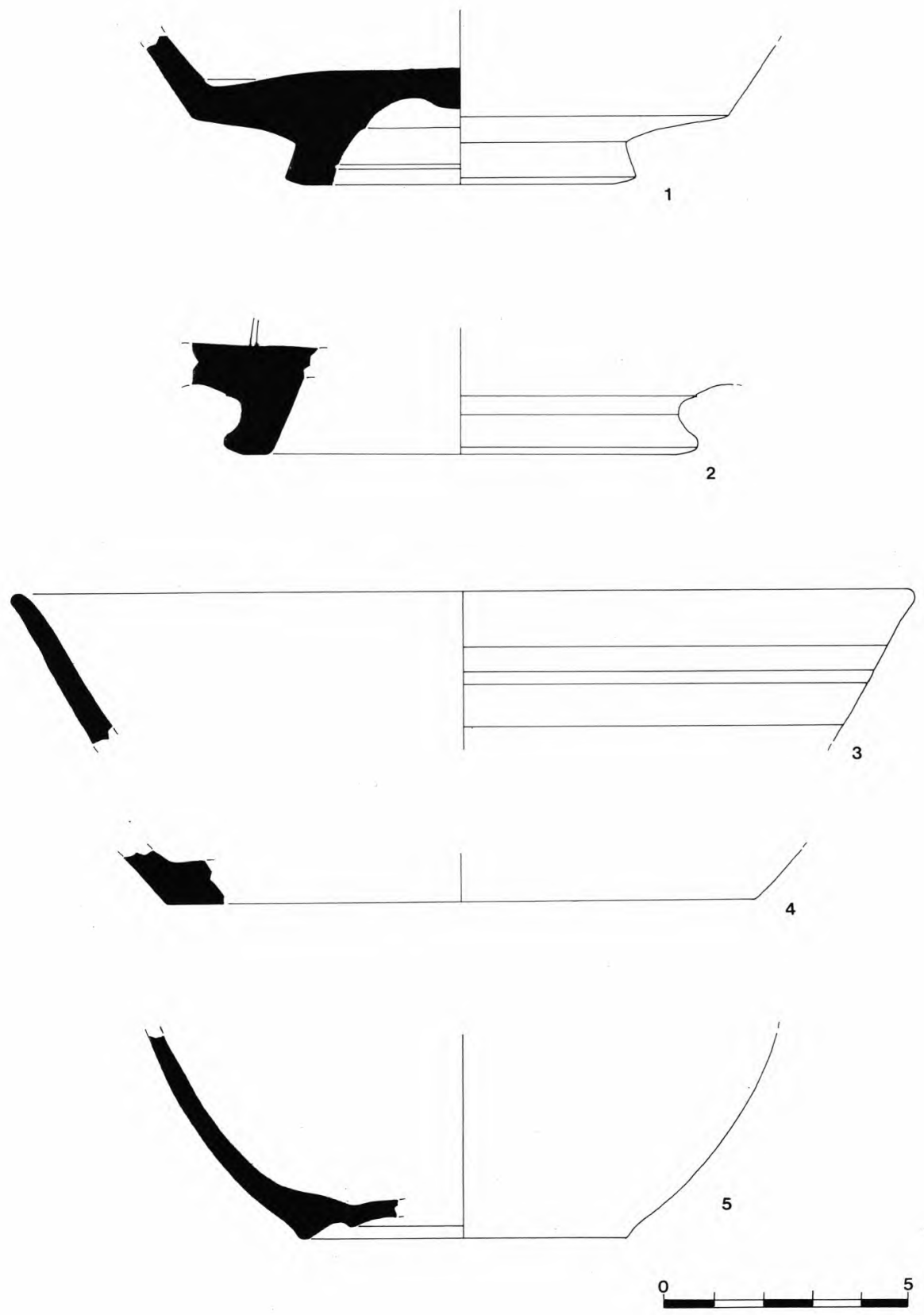
EST. II
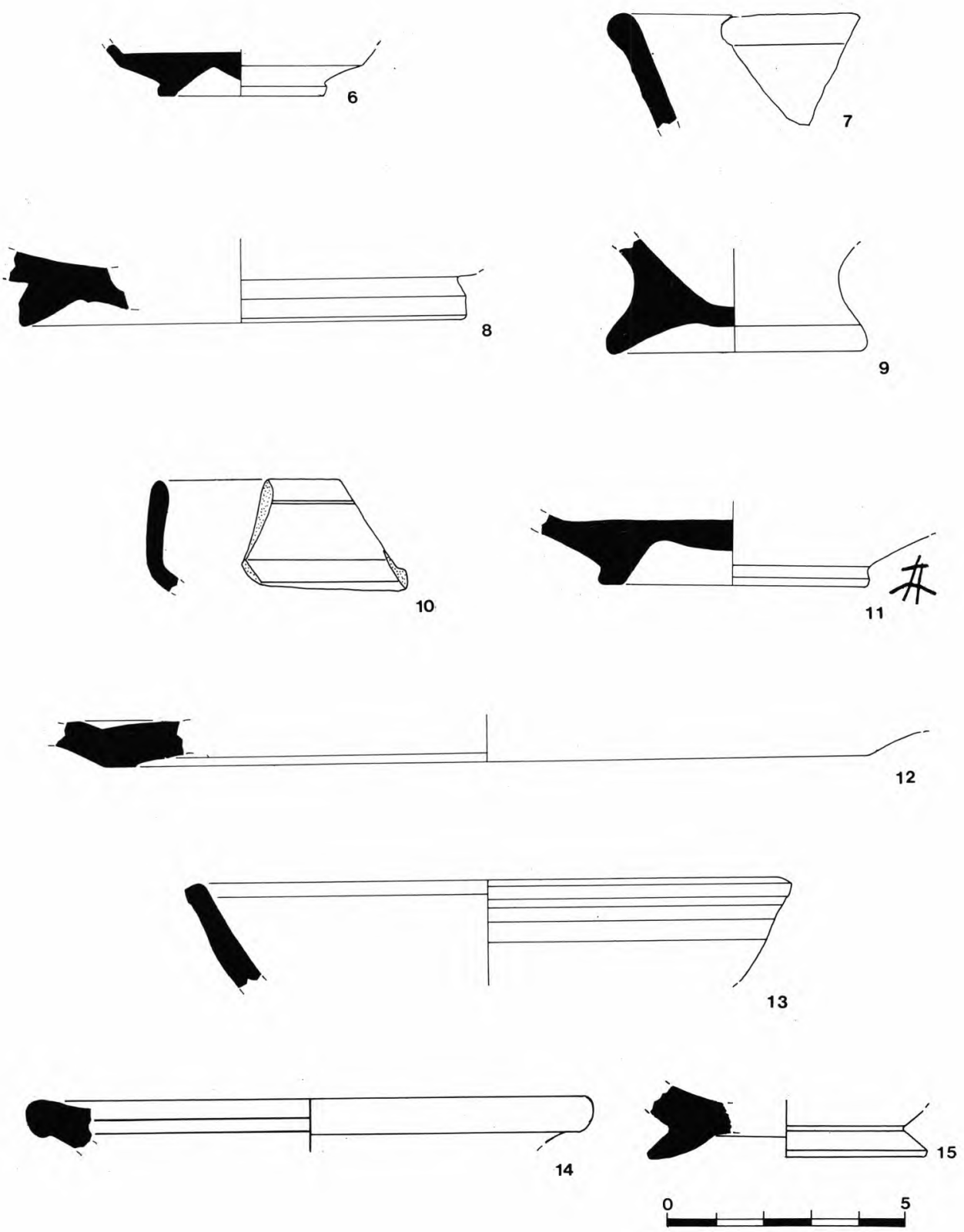